\title{
The Association of Temporomandibular Disorders and Orthognathic
} Surgery

\author{
Kadir $K^{* 1}$, Khor $K X^{2}$, Loh YT2 \\ ${ }^{1}$ Department of Oral \& Maxillofacial Clinical Sciences, Faculty of Dentistry, University Malaya, Kuala Lumpur, \\ Malaysia \\ ${ }^{2}$ Faculty of Dentistry, University of Malaya, Kuala Lumpur.
}

\begin{abstract}
This retrospective study aimed to determine the prevalence of temporomandibular disorder (TMD) secondary to orthognathic surgery (OGS) in various types of dentofacial deformities, to access the relationship of new onset of TMD in different types of OGS to pain-related TMD and intraarticular TMD, and to evaluate the chronic facial pain, temporomandibular joint (TMJ) function, and masticatory efficiency after OGS.

A total of 26 patients who were previously treated with OGS in University Malaya Medical Centre, Kuala Lumpur from January 2005 to June 2015 agreed to participate. The subjects had either undergone bilateral sagittal split ramus osteotomy (BSSRO) or bimaxillary osteotomy (BIMAX). All subjects were assessed using Diagnostic Criteria for Temporomandibular Disorder (DC/TMD). Data collected from patients' records showed absence of TMD at presurgical stage. The present study showed $42.3 \%$ of 26 patients experienced TMD after OGS in various types of dentofacial deformities, $19.2 \%$ of them presented with post-operative facial pain, $30.8 \%$ had limitation in mastication, $19.2 \%$ experienced limitation in mobility of the jaw, and $11.5 \%$ of them experienced limitation in verbal and emotional commences. In conclusion, there was no association between prevalence of TMD secondary to OGS in either type of dentofacial deformities or type of surgery involved. We also noted that the minority of the patients suffered chronic facial pain and jaw function limitation after OGS.
\end{abstract}

Keywords: Dentofacial deformities, facial pain, jaw, orthodontic, orthognathic surgery, temporomandibular joint disorder

\section{INTRODUCTION}

Orthognathic surgery is defined as surgical procedures designed to correct abnormal positioning of the jaw bones; or of relating to such surgery (1). It is always recommended when orthodontic treatment by itself is not able to correct the predicament, especially in correcting the skeletal discrepancies of the jaws and face, or problems related to structure, growth, malocclusion, TMD, and sleep apnea (2). There are 2 types of OGS, which involve either maxillary, mandibular, or both arches. For maxillary
OGS, Le Fort I osteotomy is the most common and was first published by Wassmund in 1927. The procedure is still carried out today to correct skeletal discrepancies (3). For the mandibular OGS, there are several types of surgery, which include vertical ramus osteotomy, vertical subcondylar osteotomy, inverted $\mathrm{L}$ and $\mathrm{C}$ ramus osteotomy, bilateral sagittal split ramus osteotomy (BSSRO), horizontal osteotomy, subapical osteotomy, and total alveolar osteotomy (4). However, the commonly performed mandibular OGS worldwide is the BSSRO. 
The Asian community is proven to have higher severity in dentofacial deformities especially among young Chinese adults (5). Most patients who underwent OGS had mandibular prognathism with class III skeletal pattern (6). Like every other surgery, OGS has its complications as well. The most commonly found complications are nerve damage $(12.1 \%)$, infection $(3.4 \%)$, problems with fixative materials $(2.5 \%)$, TMD $(2.1 \%)$, undue fracture $(1.8 \%)$, scarring problems $(1.7 \%)$, and hemorrhage $(1.4 \%)(7)$.

TMD is defined as a muscular and articular disorder, which includes anatomical, histological, and functional anomalies in the functioning of the muscular and/or articular components of the system that are accompanied by highly varied clinical signs and symptoms (8). The common complaints of TMD patients are clicking sounds, pain, headaches, limited mouth opening, masticatory difficulty, and mandibular deviation(8)(9)(10). There is always a strong relationship between OGS and TMD in either way $(9,10,11,13)$. TMD could be attributed by post-surgical changes of the condylar position in the glenoid fossa (14). Abrahamsson et al (2013) found out that OGS often has a good outcome on improving the signs and symptoms of TMD including headaches (10).Interestingly, Togashi et al (2012) discovered that there was still an opportunity for asymptomatic patients to develop TMD after OGS; the percentage, however, was very low (11). The author also agreed that OGS actually benefits patients with dentofacial deformities associated with TMD (11). Nevertheless, there were other researchers who reported that OGS worsens the conditions of the $\operatorname{TMD}(9,13)$.

In this research study, we aimed to determine the prevalence of TMD secondary to OGS in various types of dentofacial deformities and to assess the relationship of new onset of TMD in different types of OGS to pain-related TMD and intraarticular TMD. We also evaluated chronic facial pain, TMJ function, and masticatory efficiency after OGS. We hope our study can help future surgeons to understand and better explain to patients the risks and benefits especially related to the TMJ - of OGS before going through said procedure.

\section{MATERIALS AND METHODS}

\section{Study Design}

This was a retrospective study whereby the sample population was recruited from patients who attended the Oral \& Maxillofacial Surgical Clinic of University Malaya Medical Centre, Kuala Lumpur with various dentofacial deformities previously treated with OGS between 2005 and 2015.

The data concerning surgical history such as pre-surgical dentofacial deformities, type of surgical procedure, date of surgery, and preoperative TMD status were extracted from the dental records of the Department of Oro-maxillofacial Surgical and Medical Sciences.

The inclusion criteria were patients who had malocclusions with skeletal discrepancies and underwent OGS to correct the dentofacial deformities. The procedures included BSSRO for correction of mandible and for maxilla either a single Le Fort I osteotomy or segmental. The subjects could either have undergone mandibular osteotomy itself or a combination of both maxillary osteotomies. Patients with craniofacial deformities or clefting were excluded; however patients with obstructive sleep apnea were included (9). On the other hand, patients who underwent single genioplasty procedure, single maxillary osteotomy, or maxillary osteotomies other than Le Fort 1, or who were denture wearers were excluded $(15,16)$. All subjects had been followed up for at least 6 months after the OGS (9).

\section{Methods}

All subjects were assessed using DC/TMD which comprised of Axis I and Axis II. The components of Axis I include TMD-Pain screener, symptom questionnaire, and DC/TMD examination form. From Axis I, TMD can be diagnosed and classified into 2 groups. They are pain-related TMD and intra-articular TMD. The sub-diagnoses of pain-related TMD include: i) myalgia, ii) myofascial pain with referral arthralgia, and iii) headache attributed to TMD. In addition, the sub-diagnoses of intra-articular TMD include: i) disc displacement with reduction, ii) disc displacement with reduction, with intermittent locking, iii) disc displacement without reduction, with limited opening, iv) disc displacement without reduction, without limited opening, v) degenerative joint disease, and vi) dislocation. For clinical examination, there were many components that were examined such as opening movement, lateral and protrusive movements, TMJ noises during opening and closing movements, TMJ noises during lateral and protrusive movements, joint locking, muscle pain and TMJ pain with palpation. The clinical examination was referred from diagnostic criteria for TMD clinical protocols and assessment instruments (17).

Axis II was used to assess the patients' psychosocial status and pain-related disability. The components of Axis II include: i) Pain drawing, ii) 
Graded Chronic Pain Version 2 (GCPSV 2), iii) Jaw Functional Limitations Scale-8-item (JFLS-8), iv) Jaw Functional Limitations Scale-20-item (JFLS20 , v) Patient Health Question-4, vi) Patient Health Questionnaire-9, vii) GAD-7, viii) Patient Health Questionnaire-15: Physical Symptoms, and ix) The Oral Behavior Checklist. GCPSV 2 was used to assess the chronic facial pain after OGS and categorizes chronic pain into 5 groups which were Grade $0,1,2,3$, and 4 (18). JFLS-20 was used to evaluate the TMJ function and masticatory efficiency after surgery and were further recorded on a $0-3$ scale (19).

\section{Statistical Analysis}

All collected data were analyzed using SPSS version 12.0.1 for Windows. The prevalence of TMD secondary to OGS in various types of dentofacial deformities was analyzed using Likelihood Ratio of Chi-Square Tests. The Pearson Chi-Square Test was used to analyze "the relationship between types of OGS procedure and appearance of new onset TMD" and "the relationship between types of OGS procedure and appearance of new onset of intraarticular joint disorder". The relationship between types of surgical procedure and appearance of new onset of pain-related TMD was assessed using Fisher's Exact Test of Chi-Square Test. Descriptive analysis was done for chronic facial pain after OGS as well as the TMJ function and masticatory efficiency after OGS. Level of significance was set at 0.05 .

\section{RESULT}

From January 2005 to June 2015, a total of 72 patients with various dentofacial deformities were treated with OGS in University Malaya Medical Centre, Kuala Lumpur; however only 26 agreed to participate in this study. Among these, 18 patients were female and the age ranged from 19-50 years old (mean age: 27.88 years old). The presurgical diagnoses and types of surgical procedure that they underwent were tabulated in Table 1.

Data collected from patients' records showed that none of the study sample presented with history of TMD at presurgical stage. 11(42.3\%) out of 26 subjects were diagnosed with TMD after OGS. 2 out of these 11 patients were classified under painrelated TMD and both of them had myalgia whilst the other 9 patients were classified under intra-articular TMD. Of these 9 patients, 7 of them had disc displacement with reduction and 2 of them had disc displacement without reduction and without limited mouth opening Table 2.
Table 1: Characteristics of subjects $(n=26)$ with dentofacial deformities and types of OGS procedure

\begin{tabular}{|c|c|c|}
\hline Variable & Category & $\mathrm{n}(\%)$ \\
\hline \multirow[t]{2}{*}{ Gender } & Male & $8(30.8)$ \\
\hline & Female & 18(69.2) \\
\hline \multirow{3}{*}{$\begin{array}{l}\text { Presurgical } \\
\text { Dentofacial } \\
\text { Deformities }\end{array}$} & Class I malocclusion on & $1(3.8)$ \\
\hline & $\begin{array}{l}\text { Class II malocclusion on } \\
\text { Class II skeletal pattern }\end{array}$ & $3(11.5)$ \\
\hline & $\begin{array}{l}\text { Class III malocclusion on } \\
\text { Class III skeletal pattern }\end{array}$ & $22(84.6)$ \\
\hline \multirow{2}{*}{$\begin{array}{l}\text { Types of Surgical } \\
\text { Procedure }\end{array}$} & BIMAX & $17(65.4)$ \\
\hline & BSSRO & $9(34.6)$ \\
\hline
\end{tabular}

BIMAX $=$ Bimaxillary Osteotomy, BSSRO $=$ Bilateral Sagittal Split Ramus Osteotomy

Table 2: Diagnosis of TMD on post-operative examination

\begin{tabular}{|c|c|c|c|c|c|}
\hline $\begin{array}{l}\text { Diagnosis } \\
\text { of TMD }\end{array}$ & $\begin{array}{l}\text { Sub } \\
\text { group } \\
\text { of TMD }\end{array}$ & $\begin{array}{l}\text { Sub diagnosis } \\
\text { of TMD }\end{array}$ & $\begin{array}{l}\mathrm{n} 1 \\
(\%)\end{array}$ & $\begin{array}{l}\mathrm{n} 2 \\
(\%)\end{array}$ & $\begin{array}{l}\text { n3 } \\
(\%)\end{array}$ \\
\hline Absent & & & & & $\begin{array}{l}15 \\
(57.7)\end{array}$ \\
\hline \multirow[t]{8}{*}{ Present } & $\begin{array}{l}\text { Pain- } \\
\text { related } \\
\text { TMD }\end{array}$ & Myalgia & $\begin{array}{l}2 \\
(18.2)\end{array}$ & $\begin{array}{l}2 \\
(18.2)\end{array}$ & $\begin{array}{l}11 \\
(42.3)\end{array}$ \\
\hline & & $\begin{array}{l}\text { Myofascial } \\
\text { pain with } \\
\text { referral }\end{array}$ & 0 & & \\
\hline & & Arthralgia & 0 & & \\
\hline & & $\begin{array}{l}\text { Headache } \\
\text { attributed to } \\
\text { TMD }\end{array}$ & 0 & & \\
\hline & $\begin{array}{l}\text { Intra- } \\
\text { articular } \\
\text { TMD }\end{array}$ & $\begin{array}{l}\text { Disc } \\
\text { Displacement } \\
\text { with Reduction }\end{array}$ & $\begin{array}{l}7 \\
(63.6)\end{array}$ & $\begin{array}{l}9 \\
(81.8)\end{array}$ & \\
\hline & & $\begin{array}{l}\text { Disc } \\
\text { Displacement } \\
\text { with } \\
\text { Reduction, } \\
\text { with } \\
\text { Intermittent } \\
\text { Locking }\end{array}$ & 0 & & \\
\hline & & $\begin{array}{l}\text { Disc } \\
\text { Displacement } \\
\text { without } \\
\text { Reduction, } \\
\text { with Limited } \\
\text { Opening }\end{array}$ & 0 & & \\
\hline & & $\begin{array}{l}\text { Disc } \\
\text { Displacement } \\
\text { without } \\
\text { Reduction, } \\
\text { without }\end{array}$ & $\begin{array}{l}2 \\
(18.2)\end{array}$ & & \\
\hline
\end{tabular}




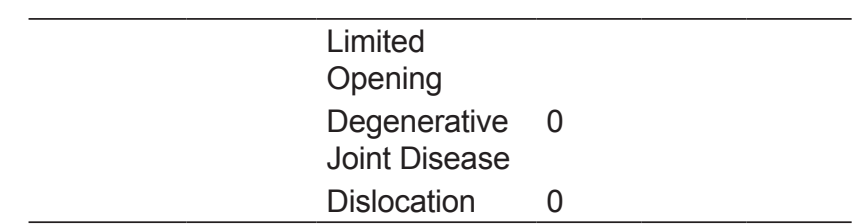

$\mathrm{n} 1=$ number of subjects with sub diagnosis of TMD

n2 $=$ number of subjects in sub group of TMD

$n 3=$ number of subjects diagnosed as TMD

Most of the subjects had class III malocclusion on class III skeletal pattern $(n=22) .8$ of these 22 patients presented with TMD after OGS surgery. Notably, 2 out of 3 patients with class II malocclusion on class II skeletal pattern also presented with TMD after orthognathic surgery. Interestingly, TMD after OGS surgery did occur to the one patient with class I malocclusion on class I skeletal pattern patient. However, from the Likelihood Ratio of Chi-Square Tests, there was no statistically significant association between types of presurgical dentofacial deformities and prevalence of TMD secondary to orthognathic surgery $(p=0.251$, Table 3$)$

Table 3: Diagnosis of TMD in various type of presurgical dentofacial deformities

\begin{tabular}{lccc}
\hline $\begin{array}{l}\text { Presurgical Dentofacial } \\
\text { Deformities }\end{array}$ & \multicolumn{2}{c}{ Diagnosis of TMD } & total \\
\cline { 2 - 3 } & $\begin{array}{c}\text { Present } \\
(\mathrm{n} 1, \%)\end{array}$ & $\begin{array}{c}\text { Absent } \\
(\mathrm{n} 2, \%)\end{array}$ & \\
\hline $\begin{array}{l}\text { Class I malocclusion in class I } \\
\text { skeletal pattern }\end{array}$ & $1(100)$ & 0 & 1 \\
$\begin{array}{l}\text { Class II malocclusion in class } \\
\text { II skeletal pattern }\end{array}$ & $2(66.7)$ & $1(33.3)$ & 3 \\
\hline $\begin{array}{l}\text { Class III malocclusion in class } \\
\text { III skeletal pattern }\end{array}$ & $8(36.4)$ & $14(63.6)$ & 22 \\
\hline Total & $11(42.3)$ & $15(57.7)$ & 26 \\
\hline
\end{tabular}

$\mathrm{n} 1$ : number of subjects showed presence of TMD

n2: number of subjects showed absence of TMD

*From the Likelihood Ratio of Chi-Square Tests, $p=0.251$, there is no association between presurgical dentofacial deformities and prevalence of TMD

A total of 11 cases of TMD were noted after OGS. 2 of these were related to myalgia (painrelated TMD); one had received BSSRO and the other BIMAX surgery. When analysed, there was no statistically significant association between types of surgical procedure and pain-related TMD, $p=0.582$. Apart from that, of the other 9 cases found to have intraarticular TMD, 3 of them had undergone BSSRO only while the other 6 had undergone BIMAX surgery. Similarly, there was no statistically significant association between types of surgical procedure and the intraarticular TMD, $p=0.920$. In a nutshell, there was no statistically significant association between the types of surgery and the occurrence of TMD for both pain and intraarticular associated TMD (Table 4).

Table 4: Appearance of new onset of TMD in different types of OGS

\begin{tabular}{|c|c|c|c|c|c|c|}
\hline \multirow{4}{*}{$\begin{array}{l}\text { Type of } \\
\text { Orthog- } \\
\text { nathic } \\
\text { Surgery }\end{array}$} & \multicolumn{5}{|c|}{ Diagnosis of TMD } & \multirow{4}{*}{ Total $_{4}$} \\
\hline & Preoper & ative & Postope & rative & & \\
\hline & \multirow[b]{2}{*}{ Absent } & \multirow[b]{2}{*}{ Present } & \multirow[b]{2}{*}{ Absent } & \multicolumn{2}{|l|}{ Present } & \\
\hline & & & & $\begin{array}{l}\text { Pain- } \\
\text { related } \\
\operatorname{TMD}(n)\end{array}$ & $\begin{array}{l}\text { Intra- } \\
\text { articular } \\
\text { TMD(n) }\end{array}$ & \\
\hline BSSRO & 9 & 0 & 5 & 1 & 3 & 9 \\
\hline BIMAX & 17 & 0 & 10 & 1 & 6 & 17 \\
\hline Total $_{1}$ & & & & 2 & 9 & \\
\hline Total $_{2}$ & 26 & 0 & 15 & 11 & & \\
\hline Total $_{3}$ & 26 & & 26 & & & 26 \\
\hline
\end{tabular}

BIMAX: Bimaxillary Osteotomy; BSSRO: Bilateral Sagittal Split Ramus Osteotomy

Total 1 : number of subjects in subgroup of TMD

Total $_{2}$ : number of subjects diagnosed with TMD

Total : number of subjects in study

$\mathrm{Total}_{4}$ : number of subjects in different types of surgical procedure

i) From Fisher's Exact Test of Chi-Square Test, $p=0.582$, there was no statistically significant association between types of surgical procedure and pain-related TMD .

ii) From the Pearson Chi-Square Test, $p=0.920$, there was no statistically significant association between types of surgical procedure and intra-articular TMD.

iii) From the Pearson Chi-Square Test, $p=0.873$, there was no statistically significant association between types of surgical procedure and appearance of new onset TMD.

Only 5 out of 26 patients (19.2\%) presented with post-operative facial pain. 3 of these patients (11.5\%) had Grade I (Low intensity, Low Interference) while another 2 patients (7.7\%) had Grade II (High intensity) facial pain (Table 5). 3 of those with facial pain were diagnosed with TMD which were myalgia and disc displacement with reduction. The shortest duration of pain in the last 6 months was 10 days while the longest duration was 120 days. 2 out of 5 patients underwent BSSRO and the remaining 3 underwent BIMAX surgery Table 6. 
Table 5: Preoperative and Postoperative Graded Chronic Pain Scale Version 2.0

\begin{tabular}{lcc}
\hline $\begin{array}{l}\text { Graded Chronic } \\
\text { Pain Scale }\end{array}$ & $\begin{array}{c}\text { Preoperative } \\
(\mathrm{n}, \%)\end{array}$ & $\begin{array}{c}\text { Postoperative } \\
(\mathrm{n}, \%)\end{array}$ \\
\hline Grade 0 & $26(100)$ & $21(80.8)$ \\
\hline Grade I & 0 & $3(11.5)$ \\
Grade II & 0 & $2(7.7)$ \\
Grade III & 0 & 0 \\
Grade IV & 0 & 0 \\
Total & 26 & 26 \\
\hline Grade 0 & $\begin{array}{l}: \text { No pain problem (prior 3 months) } \\
\text { Grade 1 -Low intensity, }\end{array}$ & $\begin{array}{l}\text { Characteristic pain intensity less } \\
\text { than 15 and four-item disability } \\
\text { score less than 17 }\end{array}$ \\
Grade II -High intensity & $\begin{array}{l}: \text { Characteristic pain intensity of 15 } \\
\text { or greater and four item. Disability }\end{array}$ \\
Grade III- Moderate interference & $\begin{array}{l}\text { Score less than 17 } \\
17 \text { to } 24\end{array}$ \\
Grade IV- Severe interference & $\begin{array}{l}: \text { Four-item Disability Score of } \\
25 \text { to } 40\end{array}$
\end{tabular}

Table 6: Details of Patient who Experienced Facial Pain in the last 6 months

\begin{tabular}{llllll}
\hline Sample & GCPSV2 & Gender & $\begin{array}{l}\text { Duration } \\
\text { of Pain* } \\
\text { (days) }\end{array}$ & $\begin{array}{l}\text { Type of } \\
\text { surgical } \\
\text { procedure }\end{array}$ & $\begin{array}{l}\text { TMD } \\
\text { diagnosis }\end{array}$ \\
\hline 1 & Grade 1 & Female & 10 & BIMAX & None \\
\hline 2 & Grade 1 & Female & 60 & BIMAX & None \\
\hline 3 & Grade 1 & Male & 24 & BIMAX & Myalgia \\
\hline 5 & Grade 2 & Female & 120 & BSSRO & Myalgia \\
\hline 5 & Grade 2 & Female & 10 & BSSRO & $\begin{array}{l}\text { Disc } \\
\text { displacement } \\
\text { with } \\
\text { reduction }\end{array}$ \\
\hline
\end{tabular}

* Duration of Pain: Duration of facial pain in the last 6 months BIMAX: Bimaxillary Osteotomy, BSSRO: Bilateral Sagittal Split Ramus Osteotomy

Graph 1: Jaw functional limitation scale-20

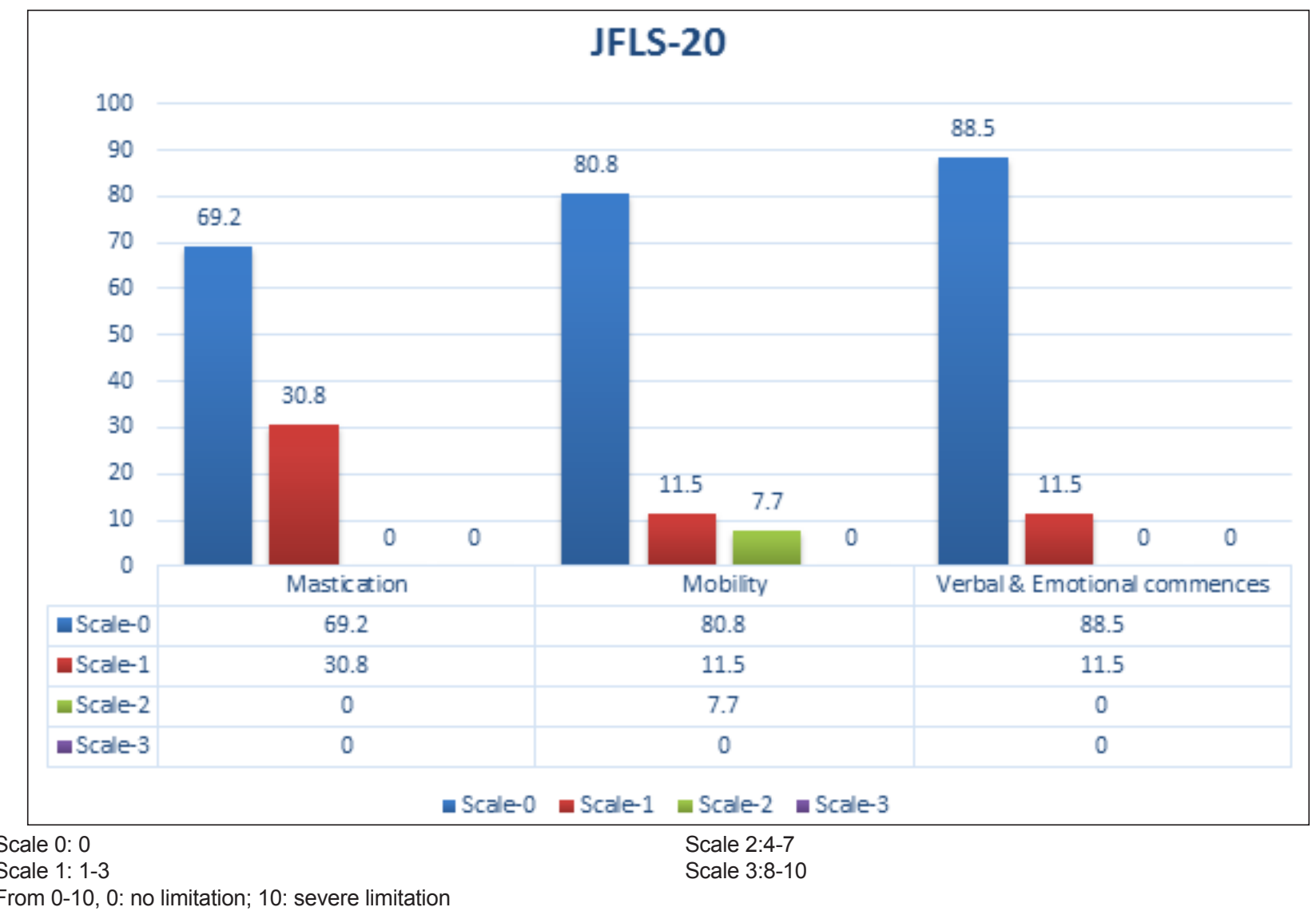

Based on Graph 1, the jaw functional limitation scale-20 items was divided into 3 groups: "mastication", "mobility" and "verbal and emotional commences". The scale was also categorized into
4 subgroups, where scale 0 indicated no limitation and scale 3 indicated severe limitation. From the study population, $30.8 \%$ of the patients experienced limitation in mastication of scale 1 and within the 
same population $19.2 \%$ of them suffered some form of limitation in jaw mobility. In addition, $11.5 \%$ out of 26 patients reported having difficulty in verbal and emotional commences of scale 1.

\section{DISCUSSION}

To date, we could only find 4 other studies that used RDC/TMD as a diagnostic tool to evaluate the occurrence of TMD in patients who underwent OGS. These studies were done by Farella et al (2007) (15), Abrahamsson et al (2009) (20), Mladenovic' et al (2013) (21), and again Abrahamsson et al (2013) (10). Up to the write up of this report, we were the first to use the DC/TMD form as a diagnostic tool which was a modified and more advanced version of RDC/TMD of the year 2014. Hence, there were limitations in comparing the data between these studies. Most of the previous studies relating to TMD in OGS utilized Helkimo and modified Helkimo index as the diagnostic tool and the classification of TMD. (22)

In the present study, there was no statistically significant association between presurgical dentofacial deformties and the prevalence of TMD secondary to OGS. Farella et al and Mladenovic'et al in their study included patients with class III malocclusion in class III skeletal pattern only (14, 21). Meanwhile, Abrahamsson et al in both of their studies included both class II and class III skeletal pattern $(10,20)$. Our study managed to capture the various types of dentofacial deformities, which are class I malocclusion on class I skeletal pattern which presented with bimaxillary proclination, class II malocclusion on class II skeletal pattern and class III malocclusion on class III skeletal pattern. Thus, only the data of patients with class III malocclusion in class III skeletal pattern were included for comparison. Nevertheless, the current study found a considerable number of new onset of TMD in patients $(n=8)$ with class III malocclusion on class III skeletal pattern. 5 out of these 8 cases were disc displacement with reduction, 1 case was disc displacement without reduction, and the remaining 2 cases were myalgia. Similarily, Mladenovic' et al reported $52.5 \%$ of class III malocclusion in class III skeletal pattern patient displayed TMD after OGS (21). This was in contrast to the study done by Abrahamson et al in the year 2013, wherein they found that there was significant reduction of TMD cases after OGS in patients with Class III skeletal pattern with normal vertical relationship of jaw(10). Interestingly, myofascial pain cases reduced from 13 to 4 cases, while athralgia cases reduced from 8 to 2 cases (10). Meanwhile, Farella et al found that none of their study population developed new TMD or experienced exacerbation of the TMD condition post-surgery (15).

Abrahamsson et al (2013) noted a drastic increase in incidence of osteoarthrosis cases (10). Before treatment there was only 1 case, but postsurgery there were total of 9 cases of osteoarthrosis (20). However, none of the degenerative joint disease cases were found in the present study or by other authors $(15,21)$.

In the present study, 7 (26.9\%) out of 26 patients reported with TMD following BIMAX surgery. This finding is similar to the result $(28.6 \%, n=14)$ reported by Farella et al where the same type of surgery was applied. The current study also discovered 4 out of 26 patients $(15.4 \%)$ who had undergone BSSRO only suffered TMD. Contrarily, Mladenovic' et al reported a drastically higher occurrence $(52.5 \%)$ of the disorder in their study within the same population (21).

The inconsistencies in the results of these studies may be attributed by several components of the study design. Firstly, the sample size of the present study $(n=26)$ and the study by Farella et al $(n=14)$ were relatively small compared to Mladenovic' et al $(n=40)$ and Abrahamsson et al (2009) $(2013)(n=121)$. Another factor was the type of surgical approach. The present study involved patients who had undergone either BSSRO or BIMAX surgery, while other authors included patients treated with BIMAX surgery only (15). Abrahamsson et al included bilateral vertical ramus osteotomy for all their mandible cases with or without maxillary osteotomy. Thirdly, the types of dentofacial deformities of the patients were different in these 4 studies. Nevertheless, the number of surgeons involved in the execution of the surgery itself could have contributed to the variables in result within the present study as well as all other reported studies.

In the current study, chronic facial pain assessment was done using graded chronic pain scale version 2, while Mladenovic' et al. used the graded chronic pain scale version 1 which was extracted from Axis II RDC/TMD (23). Moreover, Mladenovic' et al reported patients with chronic pain who were diagnosed with TMD after OGS, while in the present study 2 out of 5 patients had Grade 1 chronic facial pain but were not diagnosed with TMD (Table 6) (21). For the first case, pain was not modified by jaw movement, function or parafunction while for the 
second case, there was no pain in masticatory muscle with either muscle palpation or maximum opening. Interestingly, Mladenovic' et al also reported 9.5\% out of 21 patients had no chronic pain after OGS which appears to be a dramatic contrast with the current report whereby $80.8 \%$ out of 26 patients are free of the same complication. Another study by Luo et al assessed the postoperative ongoing pain after 1 year of OGS by using standardized Quantitative Sensory Testing protocol (25). They reported $21.4 \%$ patients had postoperative ongoing pain (25).

JFLS-20 was used in the present study to measure the functional limitation of the jaw; it is an organ-specific instrument composing 3 components which are "mastication", "vertical jaw mobility", and "verbal and emotional commences". Due to the nature of the study design (retrospective study), we were unable to identify whether those patients with functional limitations after OGS had the same presentation prior to surgery, even though clinical records showed that all the patients in the study population were absent of TMD at preoperative stage. However, in another previous study, evidence showed that patients with poor chewing performances before surgery had a tendency to improve, whereas patients with high chewing performances before surgery did not have any changes after surgery (23). For the jaw mobility, some authors used maximum mouth opening (MMO) as one of the diagnostic tools to determine the jaw mobility instead of using JLFS$20(24,26)$. They compared the preoperative and postoperative MMO to determine the mandibular mobility. Ko et al (2012) reported that the degradation in the mandibular motion after surgery could be recovered totally after 6 months and that the mandibular movement remained the same with the control group (24). Throckmorton et al (1995) also reported that although jaw hypomobility manifested at 6 weeks after surgery, it returned to normal values between 12 to 24 months (26). Some of the patients in the current study answered the questionnaire at 6 months post-surgery and we noted $11.5 \%$ of the patients were facing stage 1 limitation of jaw mobility and another $7.7 \%$ of them were experiencing stage 2 limitation.

Several limitations were encountered along the implementation of this study. First and foremost, inclusion of various types of dentofacial deformities was one of the confounding factors (22), as it complicated the data comparison among studies. The second limitation was the preoperative diagnosis of TMD. The data of preoperative diagnosis of TMD were retrieved from the dental records of patients.
The current DC/TMD tool was not applied at preoperative stage and there were different types of TMD diagnostic tools used by the previous clinicians to examine the TMJ. Thirdly, there were variables of duration for postsurgical examination. The shortest duration was 6 months while the longest was 9 years. The contributing factors of TMD were unclear as it could be attributed by other factors beside the surgery. Hence, for future studies, we would highly recommend for this research to be conducted in prospective design by applying the same diagnostic tool (DC/TMD) in pre and post-operative phase. Nevertheless, by having the study done in prospective way, we would also be able to include control group (patients diagnosed with dentofacial deformities but refused any surgical interventions) within the analysis.

\section{CONCLUSION}

In conclusion, TMD secondary to OGS were not associated to various types of dentofacial deformities. There was no association between new onset of TMD nor its sub-diagnosis (intraarticular TMD and painrelated TMD) and type of OGS. We also concluded there was a minority of the patients that encountered chronic facial pain and jaw function limitations after the OGS. However, within the database, $42.3 \%$ of the sample did suffer TMD after OGS and this warrants for further study.

\section{ACKNOWLEDGEMENTS}

The authors wish to thank the statistician Miss Najihah binti Lokman for the statistical assistance and all the dental staff for the helpful assistance during the period of data collection.

\section{Declaration of Interest}

The authors report no conflicts of interest. The authors alone are responsible for the content and writing of the paper.

\section{REFERENCES}

1. "orthognathic, adj." OED Online. Oxford University Press, September 2015. Web. 2 November 2015.

2. Sana T, Raffi S, Muhammad WI, Muhammad NK. Esthetics, Functional, And Psychosocial Satisfaction after Orthognathic Surgery 
in Patients Having Dentofacial Skeletal Deformities. Pakistan Oral \& Dental Journal. 2015; 35(3): 395-400.

3. Perciaccante VJ, Bays RA. ORTHOGNATHIC SURGERY: Maxillary Orthognathic Surgery. In, Peterson's Principles of Oral \& Maxillofacial Surgery, People's Medical Publishing House USA Ltd (PMPH) 2004: pp 1179-1204.

4. Bloomquist DS, Lee JJ. ORTHOGNATHIC SURGERY: Principles of Mandibular Orthognathic Surgery. In, Peterson's Principles of Oral \& Maxillofacial Surgery, People's Medical Publishing House USA Ltd (PMPH) 2004: pp 1135 - 1178.

5. Chew MT. Spectrum and management of dentofacial deformities in a multiethnic Asian population. Angle Orthod. 2006; 76(5): 806-809.

6. Ong MAH. Spectrum of dentofacial deformities: a retrospective survey. ANNALS-ACADEMY OF MEDICINE SINGAPORE 2004; 33(2): 239-242.

7. Sousa CS, Turrini RNT. Complications in orthognathic surgery: a comprehensive review. J Oral Maxillofac Surg Med Pathol. 2012; 24(2): 67-74.

8. Laplanche O, Ehrmann E, Pedeutour P, Duminil G. TMD clinical diagnostic classification (Temporo Mandibular Disorders). Journal of Dentofacial Anomalies and Orthodontics. 2012; 15(02): 202.

9. Dujoncquoy JP, Ferri J, Raoul G, Kleinheinz J. Temporomandibular joint dysfunction and orthognathic surgery: a retrospective study. Head Face Med. 2012; 6(1): 27.

10. Abrahamsson $C$, Henrikson T, Nilner M, Sunzel B, Bondemark L, Ekberg E. TMD before and after correction of dentofacial deformities by orthodontic and orthognathic treatment. Int J Oral Maxillofac Surg. 2013; 42(6): 752-758.

11. Togashi M, Kobayashi T, Hasebe D, Funayama A, Mikami T, Saito I, et al. Effects of surgical orthodontic treatment for dentofacial deformities on signs and symptoms of temporomandibular joint. J Oral Maxillofac Surg Med Pathol. 2013; 25(1): 18-23.

12. Schiffman E, Ohrbach R, Truelove E, Look J, Anderson G, Goulet JP, et al. Diagnostic criteria for temporomandibular disorders (DC/ TMD) for clinical and research applications: recommendations of the International RDC/ TMD Consortium Network and Orofacial Pain Special Interest Group. J Oral Facial Pain Headache. 2014; 28(1): 6-27.
13. Bays RA, Bouloux GF. Complications of orthognathic surgery. Oral Maxillofac Surg Clin North Am. 2003; 15(2): 229-242.

14. Alder ME, Deahl ST, Matteson SR., Van Sickels JE, Tiner BD, RughJD. Short-term changes of condylar position after sagittal split osteotomy for mandibular advancement. Oral Surg Oral Med Oral Pathol Oral Radiol Endod 1999; 87(2): 159-165.

15. Farella M, Michelotti A., Bocchino T, Cimino R, Laino A, Steenks MH. Effects of orthognathic surgery for class III malocclusion on signs and symptoms of temporomandibular disorders and on pressure pain thresholds of the jaw muscles. Int J Oral Maxillofac Surg. 2007; 36(7): 583-587.

16. Scolozzi P, Wandeler PA, Courvoisier DS. Can clinical factors predict postoperative temporomandibular disorders in orthognathic patients? A retrospective study of 219 patients. Oral Surg Oral Med Oral Pathol Oral Radiol Endod. 2015; 119(5): 531-538.

17. Ohrbach R. Diagnostic Criteria for Temporomandibular Disorder Clinical Protocol and Assessment Instruments. International RDC-TMD Consortium Network [updated 2014 January 29, cited 2015 November 26.] Available from http://www.rdc-tmdinternational. org/TMDAssessmentDiagnosis/DCTMD.aspx

18. Turk DC, Melzack R. Handbook of Pain Assessment. New York: Guilford Press, 2001. Print.

19. Ohrhach R, Larsson P, List T. The jaw functional limitation scale: development, reliability, and validity of 8-item and 20 -item versions. J Orofac Pain. 2008; 22(3): 219-230.

20. Abrahamsson $C$, Ekberg EC, Henrikson $T$, Nilner M, Sunzel B, Bondemark L. TMD in consecutive patients referred for orthognathic surgery. Angle Orthod. 2009; 79(4): 621-627.

21. Mladenović I, Jović N, Čutović, T, Mladenović G, Kozomara R. Temporomandibular disorders after orthognathic surgery in patients with mandibular prognathism with depression as a risk factor. Acta Odontol Scand. 2013; 71(1): 57-64.

22. Al-Riyami S, Moles DR, Cunningham SJ. Orthognathic treatment and temporomandibular disorders: a systematic review. Part 1. A new quality-assessment technique and analysis of study characteristics and classifications. Am J Orthod Dentofacial Orthop. 2009; 136(5): 624-e1. 
23. Van Den Braber W, Van Der Bilt A., Van Der Glas HW, Bosman F, Rosenberg A., Koole $R$. The influence of orthognathic surgery on masticatory performance in retrognathic patients. J Oral Rehabil. 2005; 32(4): 237-241.

24. Ko EWC., Huang CS, Lo LJ, Chen YR. Longitudinal observation of mandibular motion pattern in patients with skeletal Class III malocclusion subsequent to orthognathic surgery. J Oral Maxillofac Surg. 2012; 70(2): e158-e168.

25. Luo $\mathrm{Y}$, Svensson, $\mathrm{P}$, Jensen JD, Jensen $\mathrm{T}$, Neuman B, Arendt-Nielsen L, et al. Quantitative sensory testing in patients with or without ongoing pain one year after orthognathic surgery. Journal of oral \& facial pain and headache 2013; 28(4), 306-316.

26. Throckmorton GS, Ellis E, Sinn DP. Functional characteristics of retrognathic patients before and after mandibular advancement surgery. J Oral Maxillofac Surg. 1995; 53(8): 898-908.

\section{Corresponding author:}

\section{Dr Kathreena Kadir}

Department of Oral \& Maxillofacial Clinical Sciences

Faculty of Dentistry, University Malaya

50603 Kuala Lumpur.

Tel: 03-79674807

Email Address: kathreena@um.edu.my 